\title{
Bilinguismo no Espírito Santo: reflexos no português de adultos e crianças
}

Catarina Vaz RODRIGUES *

Resumo: O objetivo do presente trabalho é delinear algumas das interferências fonéticas de L1 no português dos descendentes de imigrantes pomeranos e alemães, em particular trocas de fonemas e alterações de estrutura silábica. O corpus analisado é constituído pelas entrevistas do projeto Atlas Linguístico do Espírito Santo (ALES) em Santa Maria de Jetibá, Santa Leopoldina e em Domingos Martins e por dados coletados em escolas públicas de primeiro grau por Benincá (2008) e Haese (2007 e 2006) em Santa Maria de Jetibá, e por Shirlei Barth (2007) em Santa Leopoldina. Constatouse que muitas das dificuldades enfrentadas pelas crianças também ocorrem na fala dos adultos, o que aponta para a necessidade de um planejamento didático-pedagógico específico para as áreas bilíngues.

Palavras-chave: Geolinguística; Multilinguísmo; fonética.

Abstract: The aim of this paper is to outline some phonetic interferences related to the German and Pomeranian dialect influences on the "Capixaba Portuguese", particularly the swapping of phonemes and the changes within the syllabic structure. The corpus consists of the Atlas Linguistico do Espirito Santo (ALES) interviews in Santa Maria de Jetibá, Santa Leopoldina, Domingos Martins and the data obtained in a public primary school by Ludimilla Benincá (2008) and Aline Haese (2007 and 2006) in

* Doutorado em Linguística e Língua Portuguesa pela Universidade Estadual Paulista Júlio de Mesquita Filho (1998). Docente da Universidade Federal do Espírito Santo. Contato: vazrodrigues@terra.com.br. 
Santa Maria de Jetibá, and by Shirlei Barth (2007) in Santa Leopoldina. It is possible to notice that many children`s speech difficulties are also prevalent in adult speech, what points out to the importance of a specific pedagogic didactic plan for the bilingual areas.

Keywords: Geolinguistics; Multilingualism; Phonetic.

\section{Apresentação}

A ocupação do Espírito Santo deu-se de forma lenta e desigual. Até o início do século XIX apenas uma estreita e descontínua faixa litorânea havia sido ocupada. A fase de ocupação do interior iniciou-se pelo sul do Estado, com a vinda de mineiros e fluminenses em busca de terras. Surgiram então, nos vales do Itapemirim e do Itabapoana, os latifúndios cafeeiros e os engenhos de açúcar baseados no trabalho escravo.

Entre 1847 e 1886 começaram a chegar imigrantes europeus, principalmente italianos, alemães e poloneses, os quais desbravaram a região serrana, onde se instalaram em pequenas propriedades (anexo 1). A população teuto-capixaba, alvo deste estudo, é constituída por diferentes grupos, tais como prussianos, saxônios, hessenses e pomeranos. Há também a presença de outros grupos, também de língua alemã, como os suíços (PETRONE, 2004, p. 24). No Espírito Santo há uma clara distinção entre os pomeranos e os outros grupos germânicos e, como não foram encontradas publicações sobre a distribuição exata dos últimos, nem sobre o estágio atual do(s) dialeto(s) que falam, mesmo havendo muitos que se consideram falantes de Hunsruckisch, optou-se aqui por uma análise distinguindo-os em dois grandes grupos: pomeranos e alemães. Assim, sob a denominação alemão poderá haver a realização de qualquer dialeto alemão.

Os imigrantes dedicaram-se ao cultivo do café, produtos de subsistência e criação de animais de pequeno porte. O gado existente era leiteiro e, em geral, para consumo doméstico. Os núcleos coloniais eram baseados no trabalho familiar, e apesar de 
haver em alguns casos mais de um grupo étnico na região, o escasso contato com os luso-brasileiros favoreceu a manutenção das tradições e das línguas dos países de origem. Os imigrantes (PETRONE, 2004) foram, na região serrana, os verdadeiros desbravadores e criaram comunidades com marcas culturais, econômicas e linguísticas diferenciadas das luso-brasileiras.

Nessa região de colônias, e mesmo nas novas áreas ao norte do rio Doce, ainda hoje o português é a segunda língua de considerável parte dos descendentes, o que evidencia os fortes laços que os prendem aos valores culturais trazidos pelos antepassados. Os adultos que moram na área urbana não enfrentam dificuldades com o português, diferentemente dos que vivem na área rural e o aprenderam tardiamente. Muitos deles, conforme se constatou no decorrer das entrevistas, se alfabetizaram depois de adultos, devido à falta de escolas no interior quando eram crianças. Entre as crianças, as dificuldades enfrentadas no período de alfabetização são grandes, pois precisam aprender, simultaneamente, uma nova língua e a habilidade de escrever.

Os professores, em geral, falam apenas o português e não estão preparados para ensinar alunos bilíngues, sejam eles crianças ou adultos, o que por si só já constitui um fator complicador do processo de aprendizagem. Apesar dos avanços da linguística, informações elementares de fonologia, que poderiam auxiliar o aprendizado dos alunos, não são utilizadas pela maioria dos docentes. Princípios básicos de linguística contrastiva e análise de erros também não são aplicados.

O objetivo do presente trabalho é delinear algumas das interferências fonéticas no português dos descendentes de imigrantes pomeranos e alemães. São apresentadas aqui trocas de fonemas e alterações de estrutura silábica. O corpus analisado é constituído pelas entrevistas do projeto Atlas Linguístico do Espírito Santo (ALES) em Santa Maria de Jetibá, Santa Leopoldina e em Domingos Martins. A coleta de dados do projeto, financiado pelo CNPq, foi efetuada entre janeiro de 2006 e julho de 2007. Também são citados dados coletados em escolas públicas de primeiro grau por Benincá (2008) e Haese (2007 e 2006) em Santa 
Maria de Jetibá e por Barth (2007) em Santa Leopoldina, as quais analisaram as interferências fonéticas da língua materna das crianças no português.

\section{Língua e integração social: um tema interdisciplinar}

Nas palavras de Benveniste (1989, p. 93), a linguagem é, para o homem, o único meio de atingir o outro; ela exige e pressupõe o outro, e língua e sociedade implicam-se mutuamente. Contudo, esse processo nem sempre é simples quando os falantes vivem uma situação de assimetria linguística, seja por falarem uma variante sem prestígio ou uma língua ou dialeto minoritário. Os grupos minoritários em situação de diglossia ainda constituem um elevado contingente populacional no Espírito Santo. Esses grupos vivenciam um conflito intercultural, cujos aspectos sociolinguísticos se manifestam em uma relação assimétrica entre práticas discursivas dominantes, centradas no português, e práticas dominadas, sejam elas efetuadas em línguas indígenas ou dialetos alóctones.

Considera-se como situação de diglossia (SCHIFFMAN, 1997) aquela em que as línguas apresentam funções claramente diferenciadas: no caso em estudo, o português é a língua padrão, exigida em todas as situações formais, enquanto os dialetos alóctones só são aceitos em determinadas situações, como nas relações familiares e entre os membros dos respectivos grupos.

Entre as línguas ou dialetos minoritários e a língua dominante se estabelecem relações de deslocamento e conservação que podem apresentar a seguinte estrutura (HAMEL, 1988, p. 64):

\begin{tabular}{|c|c|c|c|c|}
\hline \multirow{4}{*}{$\begin{array}{l}\text { 1. Tendência A } \\
\text { dominante } \\
\text { 2. Equilíbrio } \\
\text { relativo de forças } \\
\text { 3. Tendência B } \\
\text { dominante }\end{array}$} & \multirow{2}{*}{\multicolumn{2}{|c|}{$\begin{array}{cc} & \text { Práticas discursivas } \\
& \text { Língua A } \\
\text { Extensão } & (->\text { uso exclusivo })\end{array}$}} & \multicolumn{2}{|r|}{$\begin{array}{c}\text { Práticas discursivas } \\
\text { Língua B }\end{array}$} \\
\hline & & & $->$ & deslocamento (-> substituição) \\
\hline & contenção & 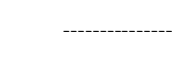 & & conservação \\
\hline & Deslocamento & (-> contenção) & & (-> normalização) \\
\hline
\end{tabular}


O caso mais comum (1) é aquele em que a língua dominante A vai pouco a pouco substituindo a língua dominada. $O$ segundo revela um relativo equilíbrio, não se registrando mudanças muito evidentes. O último caso (3) mostra a inversão do processo, tendo a língua $\mathrm{B}$ alcançado todas as áreas onde seja necessária.

No Espírito Santo, o alemão e o pomerano sofrem um processo de deslocamento, principalmente o primeiro, embora em algumas localidades a presença de ambos ainda seja expressiva, constituindo-se em núcleos de contenção. Esse processo de contenção ocorre nas áreas rurais, onde muitos adultos não falam o português ou o falam com dificuldade, e as crianças só o aprendem ao entrar para a escola. Apesar disso, as experiências e valores das comunidades representadas pelas línguas minoritárias pouca voz têm, se lembrarmos que, na maioria dos casos, o que extrapola a área das comunidades limita-se a festas e danças que muitas vezes já não são parte efetiva dessas mesmas comunidades.

Ora, se as línguas utilizadas não são eficientes para a comunicação fora das comunidades, se não são eficientes para estabelecer relações em sentido amplo, tendem a perder seu lugar como línguas vivas a longo ou médio prazo. Essa relação assimétrica não é uma sentença de morte, mas aponta para a importância do reconhecimento da existência dos dialetos e de seus usuários. Urge também a descrição e análise linguística das regiões bilíngues capixabas, o que agregará detalhamento aos problemas educacionais de indivíduos e de comunidades, favorecendo os trabalhos de planificação linguística e de políticas educativas.

O que se quer destacar é o fato de conviverem no Estado falantes que: a) dominam uma ou mais variantes do português (predominantes numericamente); b) não sabem português; c) dominam outra língua ou dialeto e uma variante do português; d) dominam tanto o português padrão quanto outra língua ou dialeto. Essa pluralidade linguística exige capacitação dos professores e planejamento didático-pedagógico específico para cada tipo de clientela.

A tradição de educação monolíngue exclui as línguas minoritárias, quando o ideal seria uma educação bilíngue. Essa 
atitude já é praticada em outros países. A Espanha, por exemplo, em sua Constituição de 1978, reconhece o catalão e o basco como línguas oficiais (GARCÍA, 1997, p. 406), e essas línguas tornaramse obrigatórias nas escolas daquelas regiões. A escola, ao ignorar a realidade das regiões bilíngues cria no educando sentimentos de baixa estima e de frustração diante dos resultados obtidos.

Entre as vantagens que a educação bilíngue traz, destaca-se a maior compreensão entre os diferentes grupos e o aumento do conhecimento de cada um por parte dos outros. Além disso,

[...] bilingual education goes beyond multicultural education because it uses language to combat racism and inequality between different language groups. In that sense, bilingual education is also encompassed within the anti-racist education movement. (GARCÍA, 1997, p.409 apud CUMMINS, 1988)

Descrever e entender a diversidade linguístico-cultural que perpassa o Espírito Santo implica (re)conhecer não apenas a língua dominante, mas também os falares minoritários, uma vez que sua presença reflete-se no português e, consequentemente, na distribuição de suas áreas linguísticas, dado que:

El desplazamiento geográfico de un grupo étnico determina generalmente un proceso de aculturación a la nueva sociedad en que pasan a residir, respondiendo a factores de tipo social, histórico, actitudinal, etc. Cuando los inmigrantes comienzan a relacionarse con miembros de la sociedad receptora, adquieren nuevas costumbres y adoptan valores culturales del nuevo entorno social, que pueden reemplazar a los propios o bien coexistir con éstos de un modo más o menos conflictivo. Al mismo tiempo, la sociedad receptora experimenta cambios en función de su propia adaptación al grupo con que entra en contacto. (BARRIOS, 2000, p. 3) 


\section{Comunidades pluriculturais e multilíngues}

Embora o ALES tenha como objetivo descrever as variantes do português, compreende dados que permitem fazer uma avaliação prévia de aspectos referentes à diversidade linguística existente no estado. Contudo, somente pesquisas futuras, específicas na área de multilinguismo, corrente importante da sociolinguística (COULMAS, 1997, p. 6-7), mas cuja metodologia não foi utilizada no ALES, poderão trazer mais detalhes sobre as línguas e dialetos em uso, bem como seus reflexos no português capixaba.

As comunidades investigadas são, portanto, constituídas por grupos étnicos minoritários, os quais conseguiram manter, após mais de um século de imigração, a língua trazida pelos antepassados e, em várias localidades, também a religião. A religião luterana se constituiu em fator de união cultural, social e de divulgação do alemão padrão, como se constata no comentário de uma informante: “[...] e na língua religiosa a gente estudou alemão. Eu e ele também, mas os nossos filhos já não, (para) esses já ensinaram português."

Consideramos os descendentes de alemães e pomeranos como grupos étnicos, dado que contam com um vínculo cultural comum herdado, se reconhecem e são reconhecidos pela língua, pela religião e pelas tradições (BARRIOS, 2000). O uso do alemão e do pomerano, a religião luterana, as festas de casamento, a confecção de alguns alimentos, a arquitetura, entre outros aspectos, distinguem a área de ocupação germânica.

Os municípios são considerados multilíngues dada a competência que seus integrantes têm, em diferentes graus, para se comunicar em duas ou mais línguas e interagir culturalmente (COÏANIZ, 2005, p. 30-31). Como observa Barrios (2000, p. $15-$ 18), a manutenção de uma língua própria aumenta as possibilidades de manutenção do grupo, mas o grau de diferenciação com a sociedade receptora também influencia em uma maior ou menor assimilação, sendo que, quanto mais diferenciadas as sociedades, mais lenta é a assimilação. 
As comunidades com imigrantes germânicos contemplam, portanto, uma série de diferentes fatores que contribuem para a preservação de sua herança linguística e cultural. Apesar disso, os dialetos são utilizados predominantemente na área rural. Nota-se, entre os jovens que partem para os centros maiores em busca de oportunidades no mercado de trabalho, o abandono do dialeto e, mesmo no caso dos descendentes monolíngues que apresentam traços fonéticos do grupo a que pertencem, a adoção dos traços linguísticos do grupo majoritário, para evitar discriminações.

Observou-se, nas áreas pesquisadas, que os usuários da língua dos antepassados são numericamente predominantes entre os descendentes de pomeranos; os falantes de alemão são menos representativos e, em termos de estado, também estão presentes em um número menor de localidades.

\subsection{Contexto histórico dos municípios}

Domingos Martins, Santa Leopoldina e Santa Maria de Jetibá foram polos da colonização alemã e pomerana. Os primeiros imigrantes alemães fundaram Santa Isabel (D. Martins) em 1847. Eram provenientes do Reno, das elevações do Hunsruck; logo depois vieram novos contingentes da mesma região e do Hesse (EL-MURR; EL-MURR; PORTAL, 1980, p. 311). Domingos Martins recebeu também italianos, os quais ocuparam Aracê e Araguaia, este último hoje distrito de Marechal Floriano.

Santa Leopoldina foi fundada pelo donatário José Claudio Souza, mas seu desenvolvimento toma impulso em 1856, com a chegada dos imigrantes suíços, alemães, luxemburgueses e pomeranos. As colônias se espalharam pelo território, bastante acidentado, dando origem a núcleos agrícolas compostos pelas diferentes etnias. Santa Leopoldina é marcadamente germânica, o que se reflete na arquitetura e na manutenção dos dialetos.

Santa Maria de Jetibá é considerado o município mais representativo dos imigrantes pomeranos, embora eles estejam presentes em Santa Leopoldina, Domingos Martins e vários outros municípios. A colonização pomerana de Santa Maria de Jetibá 
começou em 1857 e, como todos os outros imigrantes, eles se dedicaram à agricultura, a qual ainda hoje é a base da economia local.

O tipo de povoamento, feito em pequenas propriedades, em terreno acidentado, distanciava a população das respectivas sedes e tornava quase inexistentes os aglomerados urbanos. A comunicação com as localidades próximas era dificultada pelo primitivismo dos meios de transporte e pelas precárias condições das estradas. Ilustra tal precariedade o fato de, em dias de chuva, serem necessárias sete horas para percorrer os $13 \mathrm{~km}$ que separam Domingos Martins de Viana (EL-MURR; EL-MURR; PORTAL, 1980, p. 314-315).

O uso do pomerano e do alemão, embora não apresentem a mesma vitalidade em todas as localidades, ainda faz com que muitas crianças tenham seu primeiro contato com o português na escola, e muitos descendentes, em particular os pomeranos, o aprendam somente depois de adultos.

Os municípios citados têm vários pontos em comum: a colonização alóctone em pequenas propriedades, situadas nas terras frias e com relevo bastante acidentado, o predomínio do trabalho familiar, a manutenção das tradições e das línguas dos antepassados. Esses municípios apresentam imigrantes de diferentes regiões européias, fato referido pelos informantes como "variedade de cultura", "misturô tudo", o que aponta para as mútuas influências. As características da ocupação luso-brasileira praticamente não se fazem sentir nesses municípios, em tudo similares às áreas de colonização alóctone do sul do país.

\section{A coleta de dados}

Os dados aqui apresentados, referentes aos informantes adultos, fazem parte do corpus do ALES, cujo planejamento seguiu pressupostos da Geografia Linguística tradicional na definição da rede de pontos, elaboração dos questionários e traçado do perfil dos informantes. Os dados referentes aos alunos de ensino básico foram coletados por alunas de pós-graduação e de iniciação 
científica que investigavam interferências da língua materna em crianças que tinham como primeira língua o pomerano e o alemão. A dissertação de Benincá (2008) avaliou dados do português oral e escrito de crianças cursando a $5^{\mathrm{a}}$ série; Haese analisou a realização de ditongos (2006) e da estrutura silábica (2007) somente do português oral de alunos de $4^{a}$ e de $5^{a}$ séries. Ambas trabalharam com crianças de escolas públicas de primeiro grau de Santa Maria de Jetibá, as quais tinham o pomerano como L1. Barth (2007) analisou a troca de consoantes sonoras por surdas na fala de alunos da $5^{a}$ série de uma escola pública de primeiro grau de Santa Leopoldina, os quais tinham como L1 o alemão.

\subsection{A rede de pontos}

A seleção dos pontos foi feita a partir do estudo das microrregiões definidas pelo IBGE, visto reunirem características físicas, econômicas e sociais relativamente homogêneas. A seleção dos municípios que compõem a rede incluiu entre seus critérios:

a) Distribuição, para evitar que algumas áreas ficassem sem representação. O estado foi dividido em células de 5.000 $\mathrm{km}^{2}$, seguindo-se aqui um critério já utilizado no Atlas Lingüístico-Etnográfico da Região Sul (ALERS) (KOCH; KLASSMANN; ALTENHOFEN, 2002);

b) Época de ocupação: procurou-se selecionar localidades mais antigas, representativas em termos históricos e culturais; c) Caso todos os municípios de uma célula fossem relativamente novos, optava-se por aquele onde se previa, dadas suas características étnicas e culturais, maior diversidade linguística;

d) Densidade populacional: dados os objetivos da pesquisa e a metodologia adotada, foram selecionados municípios que apresentassem população rural numericamente representativa e densidade demográfica de baixa a média; e) Taxa de analfabetismo: considerando-se que conhecer a realidade linguística mostra-se o primeiro passo para uma reformulação do processo de alfabetização, caso duas 
localidades apresentassem características semelhantes em todos os quesitos, a escolha se dava em favor daquela que apresentasse o maior número de analfabetos.

O projeto previa uma rede de 30 pontos, mas foi possível acrescentar, dada a disponibilidade de verbas, mais 5 pontos na zona de ocupação mais antiga e com maior densidade demográfica, obtendo-se, assim, uma rede de 35 pontos (anexo 2).

\subsection{Os questionários}

Na elaboração dos questionários do ALES, foram incluídas questões já formuladas em outros atlas, garantindo, dessa forma, um balizamento do alcance das variantes. O questionário fonéticofonológico (QFF) segue os moldes do Atlas LingüísticoEtnográfico da Região Sul (KOCH; KLASSMANN, ALTENHOFEN, 2002) e apresenta 25 questões que averiguam a realização de consoantes e vogais em ambientes previamente estabelecidos. O questionário morfossintático (QMS) investiga apenas seis itens; entre eles há questões referentes à utilização de pronomes, gênero, número e grau. Essa parte é complementada com os dados dos discursos semidirigidos. O questionário lexical (QL) inclui 227 questões (onomasiológicas e semasiológicas) distribuídas pelos seguintes campos semânticos: acidentes geográficos, fenômenos atmosféricos, astros e tempo, flora, atividades agropastoris, fauna, convívio e comportamento social, ciclos da vida, corpo humano, religião e crenças, jogos e brincadeiras, habitação alimentação e cozinha, vestuário e acessórios.

Para o presente estudo foram utilizados dados do QFF, do QL e, principalmente, dados dos discursos semidirigidos. Os dados do QFF e do QL buscam, salvo as questões semasiológicas, uma resposta específica. São questões limitantes, em termos discursivos, mas são também uma necessidade, dados os objetivos e a metodologia de elaboração de um atlas linguístico. Os discursos semidirigidos permitem que o informante fale livremente tanto sobre os temas propostos (história da comunidade, vida dos 
antepassados, lendas, festas, etc.), quanto sobre algo que ache relevante, a respeito do que gostaria de se pronunciar (último tema, apresentado no final da entrevista). Nessa etapa da entrevista, obtém-se um discurso que fornece dados complementares, tanto fonéticos quanto lexicais e morfossintáticos, entre outros.

\subsection{Os informantes}

Os informantes adultos deviam apresentar preferencialmente as seguintes características: serem nascidos no local ou terem ali chegado ainda pequenos; serem os pais e o cônjuge da mesma localidade; serem analfabetos ou terem no máximo $4^{a}$ série; não serem muito viajados; não terem vivido muito tempo fora da localidade; terem aparelho fonador em boas condições; terem idade entre 30 e 55 anos. Para avaliar a diferença entre falas femininas e masculinas, foram entrevistados dois informantes em cada ponto: uma mulher e um homem.

O planejamento inicial previa que mesmo os descendentes de imigrantes alóctones fossem monolíngues. Contudo, em algumas localidades todos são bilíngues, salvo os poucos que para lá foram depois de adultos. Decidiu-se, assim, dada a composição étnica do Estado, entrevistar pessoas bilíngues nas localidades com predomínio de alóctones, tais como as que são aqui investigadas. Foram entrevistados sete informantes, dos quais três descendentes de pomeranos e quatro de alemães. Com relação aos primeiros, dois aprenderam L2 depois de adultos e um quando criança. Em relação aos descendentes de alemães, dois aprenderam L2 quando criança e os outros dois consideram-se monolíngues. Embora tenham sido previstos apenas dois informantes por ponto, foi incluído aqui um informante auxiliar, por ser bilíngue.

Quanto às crianças, todas deveriam ter o português como segunda língua, pois o objetivo das pesquisas de Benincá, Haese e Barth era avaliar as principais interferências fonéticas de L1 em L2. Benincá e Barth trabalharam com alunos da $5^{a}$ série e Haese com alunos de $4^{a}$ série (2006) e, posteriormente, de $5^{a}(2007)$. 


\section{Interferências no português}

As interferências da língua materna no português dos informantes mostram-se atenuadas entre os descendentes monolíngues. Convém lembrar, porém, que muitos dos que se autodenominam monolíngues frequentemente entendem o dialeto local e utilizam alguns de seus termos. Foi o que se constatou em observações tais como: "eu não falo alemão/pomerano, mas entendo alguma coisa", "em alemão/pomerano isso se chama X".

Não se pretende fazer aqui uma análise contrastiva, mas não é possível deixar de destacar algumas das diferenças entre o sistema fonológico do alemão e do pomerano em relação ao português. As dificuldades observadas foram tanto em relação à presença ou ausência de um dado fonema em uma das línguas quanto em relação à sua distribuição na sílaba.

Tanto o alemão e o pomerano quanto o português apresentam oclusivas surdas e sonoras. Contudo, há diferenças que podem dificultar a sua distinção em português: segundo Tressmann (2006), em pomerano, as surdas em posição tônica e final são sempre aspiradas, o que constitui um traço a mais para identificálas. Em alemão, as sonoras em posição final são enunciadas como surdas (LYONS, 1979, p. 120), regra que não se aplica ao português.

Exemplos de trocas de oclusivas sonoras por surdas entre adultos falantes de pomerano:

[ka'rufe] (garrucha); [kra'niz ${ }^{u}$ (granizo); [to'tej] (adotei); [pafta'su] (Baixo Itaguasu).

Quanto às constritivas, as trocas de sonoras por surdas deram-se principalmente com as alveolares e as palatais:

[te'sore] / [tfi'sore] (tesoura); [dispare'sew] (desapareceu); $\left[\mathrm{Se}^{\mathrm{m}}\right]$ (gema).

Entre as crianças, de ambos os grupos, as trocas foram mais frequentes com os fonemas oclusivos na seguinte ordem: 
bilabiais ['poj] (boi); velares ['kafu] (garfo); e dentais ['ten $\left.{ }^{\mathrm{n}} \mathrm{tu}\right]$ (dentro).

As trocas com as constritivas foram menos acentuadas, ocorrendo principalmente com as alveolares e as palatais:

['kase] (casa); ['Sun tu] (junto).

Embora a troca de sonoras por surdas seja muito frequente entre os falantes de línguas germânicas, conforme constatado em outros trabalhos, tais como o de Prade (2003), no Espírito Santo, os dados analisados até o momento confirmam parcialmente essa a firmação. Entre as crianças que falam alemão e pomerano as trocas realmente ocorrem, e são frequentes (BENINCÁ, 2008; HAESE, 2006; BARTH, 2007); contudo, entre os adultos entrevistados, as ocorrências são mais recorrentes entre os descendentes de pomeranos e raras entre os descendentes de alemães. A troca de /v/ por / f/, por exemplo, não foi registrada em nenhuma entrevista com adultos descendentes de alemães.

No estado predomina o uso de [w] em coda silábica, mas entre os bilíngues e mesmo entre alguns monolíngues descendentes de imigrantes alóctones ocorre na maioria das vezes o uso da lateral velarizada [1] e, em alguns casos, da lateral [1]:

['sol] (sol); [per'nił] (pernil); ['fałsu] (falso); [al'fas'] (alface).

Essas realizações não surpreendem se considerarmos que [1] ocorre em coda silábica em alemão ['mitəl] (Mittel: meio); [malts] (Malz: malte) e, segundo os exemplos de Tressmann (2006), também há ocorrências em pomerano de [1] e [1] em coda.

A substituição da vibrante múltipla pela tap ocorreu entre os falantes de alemão, tendo sido registradas ocorrências tais como [sera'so ${ }^{\mathrm{n}}$ ] (cerração); ['raju] (raio). A pesquisa de Barth com as crianças privilegiou a troca de sonoras por surdas, não apresentando ambientes propícios para a troca da múltipla pela tap. Note-se que 
enquanto Prade (2003, p. 90) destaca que o alemão gaúcho utiliza sempre a tap em ambientes de múltipla, no Espírito Santo esse uso não foi, entre os entrevistados, regular. Essa troca não foi efetuada pelos falantes de pomerano, pelo menos não nas localidades pesquisadas.

A troca de vogais orais ocorre principalmente entre os falantes de pomerano. Foram registradas:

a) troca da média posterior fechada por posterior alta: ['mufu ], ['mu $\left.\int^{\circ}\right]$ (mocho);

b) troca da média posterior aberta pela fechada: [isko'line];

c) troca da baixa central pela alta anterior: ['liz'] (lisa).

As crianças apresentaram poucas trocas de vogais na fala:

a) de alta posterior por alta anterior: ['livrI] (livro);

b) de média posterior fechada por média aberta: [' $\left.\mathrm{o}^{\mathrm{m}} \mathrm{b} \boldsymbol{b u}\right]$ (ombro).

Em termos de estrutura silábica, a supressão do tap em encontro consonantal foi pouco frequente na fala dos adultos ([ki'lomitos] - quilômetros), mas a supressão da tap e da nasal em coda silábica ocorreu entre informantes dos dois grupos:

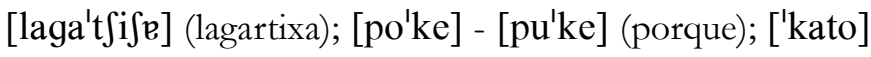 (canto).}

No último exemplo, a própria informante se autocorrigiu adiante e utilizou a trava nasal. Constatou-se que, no decorrer das entrevistas, havia uma tendência em falar mais pausadamente, e que uma maior rapidez levava a um maior número de trocas.

As crianças (BENINCÁ, 2008; BARTH, 2006) de ambos os grupos apresentaram dificuldades com a estrutura silábica do português. As mudanças ocorreram tanto em encontro consonantal quanto em coda silábica: 
a) ['tentu] (dentro); ['patu] (prato);

b) [i'Jade] (enxada); ['avore] (árvore); ['kanI] (carne).

A supressão da vogal átona final foi realizada somente pelos falantes adultos de pomerano, não tendo ocorrido entre os alemães. A supressão predomina em sílabas cujo ataque apresenta uma oclusiva e é esporádica em outros ambientes:

[ $\mathrm{u}^{\prime}$ visk] (chuvisco); ['kresp] (crespa); [istabili'dad (estabilidade); ['post] (poste); [toj'si ${ }^{\text {n}}$ ] (toucinho).

As crianças descendentes de pomeranos suprimem tanto a vogal átono final quanto a segunda consoante do encontro consonantal:

['vak] (vaca); [ma'kak] (macaco); [ Ja'neł] (janela); ['ot] (outro); ['se $\left.{ }^{\mathrm{m}} \mathrm{p}\right]$ (sempre).

As descendentes de pomeranos registraram menos ambientes com supressões:

['kəp] (copo); [xefrife'ra $\left.{ }^{\mathrm{n}} \mathrm{t}\right]$ (refrigerante).

Outro aspecto, este pouco frequente, mas constatado entre crianças e adultos, foi a inserção de vogal, como se observa em [fervi'enu] (fervendo).

$\mathrm{Na}$ fala das crianças de ambos os grupos houve a inserção de vogais formando hiatos e principalmente ditongos:

a) [piki'env] (pequeno);

b) [ a'pjeł] (chapéu); ['bwole] (bola); ['tejdu] (dedo).

Os ditongos $\left[{ }^{\mathrm{j}} \varepsilon\right]$ e [ $\left.{ }^{\mathrm{w}} \mathrm{\rho}\right]$ constam do dicionário de pomerano de Tressmann, sendo, portanto, uma transposição de L1 para o português. O ditongo $\left[{ }^{\mathrm{j}} \varepsilon\right]$ também apareceu na fala dos

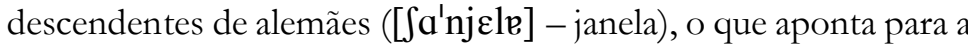
necessidade de descrição dos dialetos. 
Em relação ao ditongo / auN/, foram registradas trocas por /oN/ feitas pelos falantes de alemão, tanto adultos quanto crianças:

[te ${ }^{\mathrm{m}}$ po' $\left.^{\prime} \mathbf{o}^{\mathrm{n}}\right]$ (temporão); [so $\left.{ }^{\mathrm{m}} \mathrm{bra}^{\mathrm{l}} \mathrm{so}^{\mathrm{n}}\right]$ (assombração); [mo'ro $\left.{ }^{\mathrm{n}}\right]$ (mourão).

O ditongo / auN/ não ocorre na língua alemã, o que explica as dificuldades dos falantes. Tressmann também não o registra em seu dicionário de pomerano, mas entre os adultos não registramos sua substituição por /oN/. Contudo, Haese (2007) registrou essa troca entre crianças de ensino básico.

O apagamento da primeira sílaba quando constituída apenas por vogal baixa foi frequente tanto entre descendentes de alemães quanto de pomeranos:

[konte'sew] (aconteceu); [so ${ }^{\mathrm{m}} \mathrm{bra}^{\mathrm{n}} \mathrm{so}^{\mathrm{n}}$ ] (assombração); [kredzi'tej] (acreditei).

Embora alguns dos processos fonológicos descritos acima também ocorram fora das comunidades alóctones, mas em geral apenas entre crianças, sua frequência entre os descendentes de imigrantes é bem maior e ocorre também entre os adultos.

\section{Considerações finais}

Os dados apresentados mostram a influência que o pomerano e o alemão exercem sobre a fonética dos entrevistados. Algumas trocas de fonemas e alterações silábicas são coincidentes entre os falantes de ambos os grupos linguísticos, porém, os dados mostram que entre os adultos: a) a troca de sonoras por surdas, a troca de vogais e a supressão da vogal átona final é mais frequente entre os falantes de pomerano; b) a troca da vibrante pela tap e a alteração do ditongo nasal ocorreram entre os falantes de alemão. As interferências apontadas estão presentes tanto na fala dos bilíngues quanto, ainda que em menor grau, dos descendentes monolíngues. 
As crianças, de ambos os grupos estudados, apresentam um número maior de trocas de fonemas, principalmente de sonoras por surdas, e o apagamento da tap dos encontros consonantais, bem como a troca de vogais, também foi registrado.

Percebe-se, do exposto, que os moradores das comunidades pomeranas e alemãs apresentam dificuldades diferenciadas, o que implica procedimentos didático-pedagógicos específicos para cada grupo linguístico. Os dados aqui apresentados são uma amostra da realidade dos bilíngues capixabas e aponta para a necessidade de estudos mais abrangentes.

Um português permeado por diferentes trocas de fonemas não é o que os falantes bilíngues em línguas minoritárias almejam, é o que a escola está oferecendo ao não se instrumentalizar para atender a uma clientela que necessita de professores treinados e material didático-pedagógico específico.

Alguns passos mostram-se indispensáveis para mudar o quadro apresentado, tais como descrições detalhadas da fonologia, da morfologia e da sintaxe dos dialetos, para que possam ser tomados como parâmetro para o preparo do material didático. Professores bilíngues, com domínio de princípios de fonologia aplicados à alfabetização e de linguística contrastiva, dispondo de dados sobre ambos os dialetos e sobre o português, poderão facilitar o aprendizado de crianças e adultos. As palavras de Fernándes (2004, p. 9) vão ao encontro dessa posição e a ampliam:

[...] quando a formação se dá em dois idiomas, o futuro professor estabelece mais relações entre ambas, transfere possibilidades de trabalho da língua estrangeira para a materna, [...] ao mesmo tempo em que valoriza igualmente todas as habilidades linguísticas e não ignora a importância do conhecimento das competências sociolinguística, discursiva e estratégica, não se limitando ao desenvolvimento, nos seus alunos, da competência gramatical. 
Embora os Parâmetros Curriculares Nacionais para a Educação Fundamental no Brasil tenham a pluralidade cultural como um de seus temas curriculares transversais, muito pouco foi feito para mudar a realidade de milhares de alunos de diferentes etnias, cujas língua e cultura são literalmente ignoradas. O resultado é frustração para o educando, abandono da escola ainda nas séries iniciais e dificuldades para dominar o português, seja qual for a variante.

Muitos acusam os pais por tirarem os filhos da escola para serem "mais um braço na lavoura". Talvez fosse este o momento de pensar estratégias que levem os alunos a aprender com mais eficiência, fazendo com que os pais percebam que a escola frequentada pelos filhos não é a mesma que eles frequentaram, e não obtiveram sucesso. Além disso, se puderem dominar o português com proficiência, não sentirão a necessidade de abandonar seus dialetos para evitar as interferências. Também não terão razão para se sentirem diminuídos diante dos outros alunos ou inseguros na hora de interagir em situações formais em que o português é exigido. 
Anexo 1

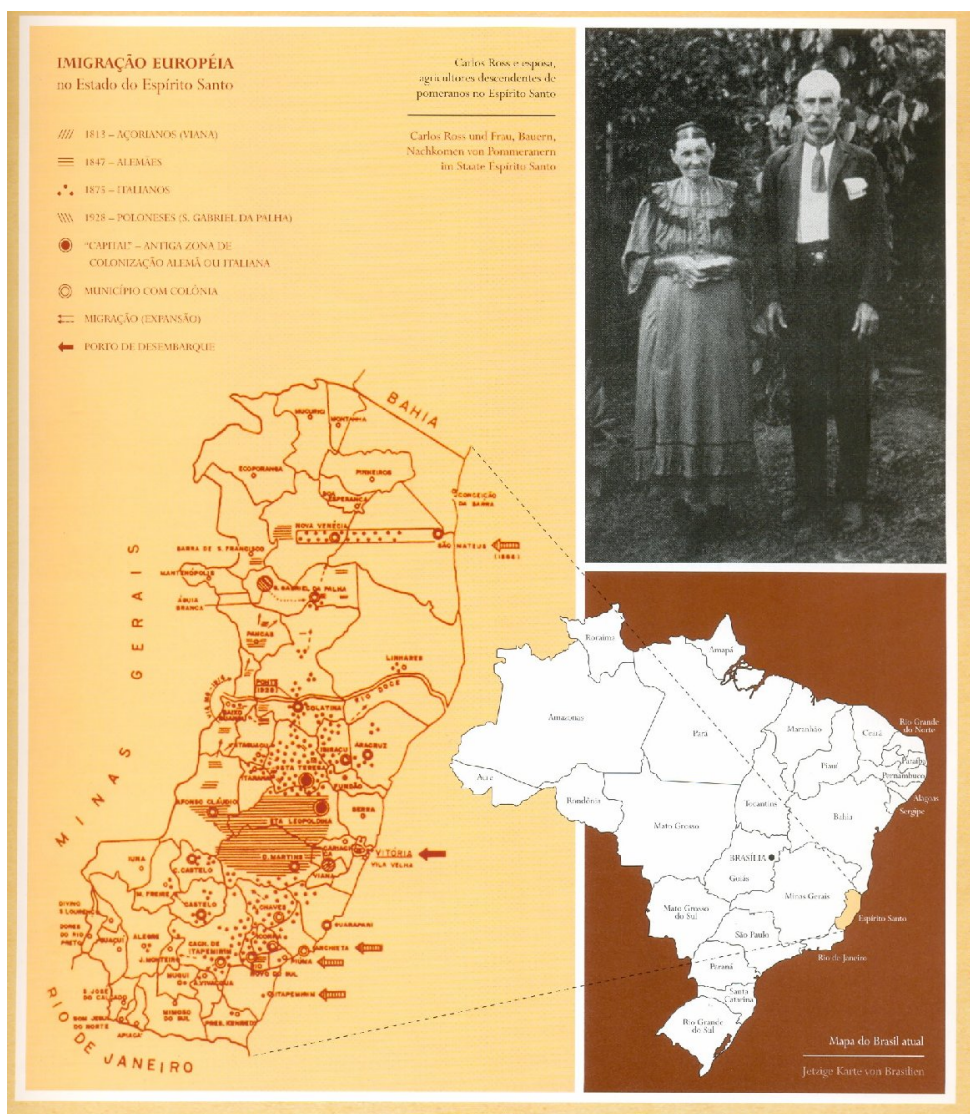


Anexo 2

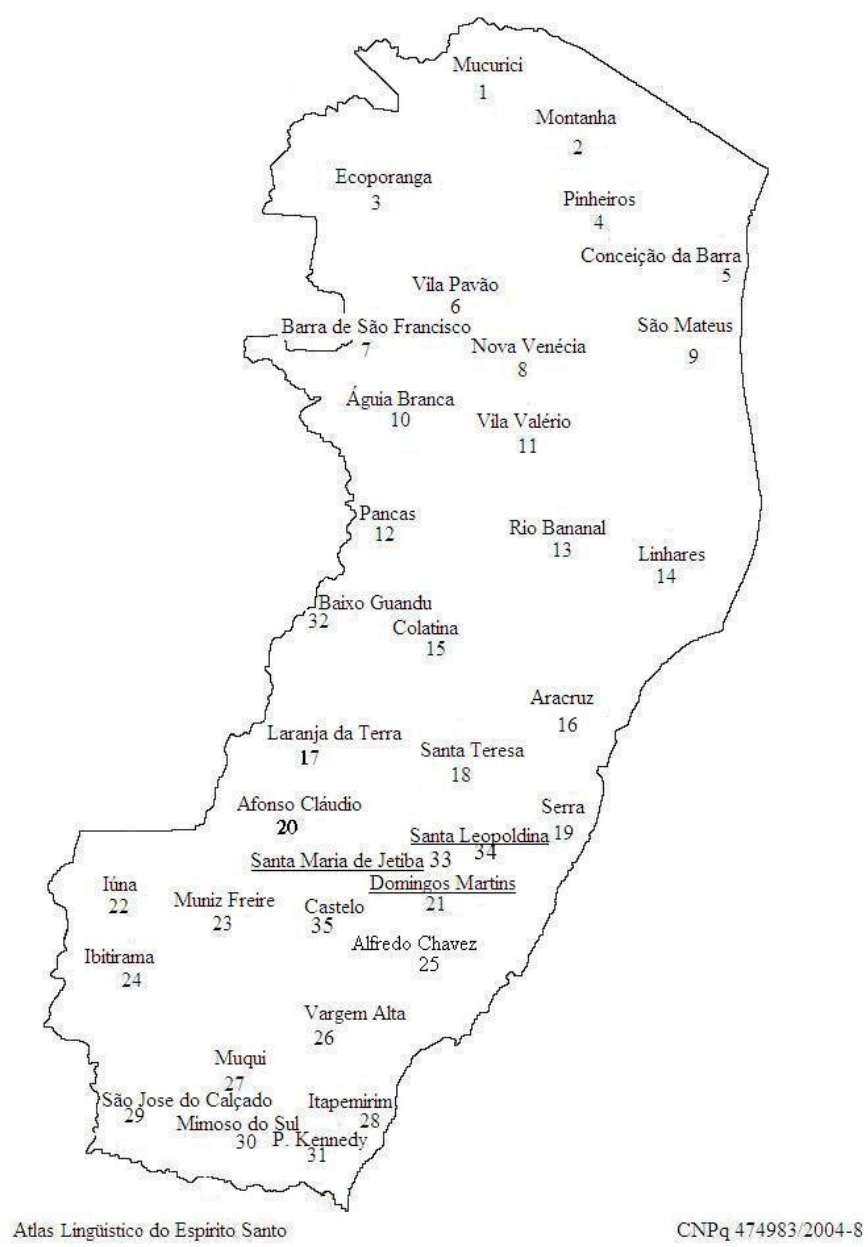




\section{Referências}

AGUILERA, Vanderci de Andrade (Org.) A geolingüística no Brasil: trilhas seguidas, caminhos a percorrer. Londrina: EDUEL, 2005. p. 319-332.

BARTH, Shirlei. Aprender o português: a árdua tarefa das crianças descendentes de alemães. Vitória: Saberes - TCC, 2007.

BARRIOS, Graciela. Construcciones y reconstrucciones discursivas, repertorio lingüístico fronterizo y enseñanza de portugués. In: MASELLO, L. (comp.) Actas del Primero Encuentro de Profesores de Portugués del Uruguay. Montevideo: CSIC/UDELAR: 2007. p. 1-22.

Etnicidad y lenguaje. La aculturación sociolingüística de los inmigrantes italianos residentes em Montevideo. Bahía Blanca, Argentina: Universidad Nacional del Sur, 2000.

.; ORLANDO, Virginia (Comp.). Marcadores sociales en el lenguaje. Estudios sobre el español hablado em Montevideo. Montevideo: Gráficos del Sur, 2002.

BENINCÁ, Ludimilla. Dificuldades no domínio dos fonemas do português por crianças descendentes de pomeranos. 2008. Dissertação (Mestrado em Estudos Linguísticos) - Universidade Federal do Espírito Santo, Vitória.

BOUTET, Josiane; VERMES, Geneviève. Multilingüismo. Trad. C. Meira et. al. Campinas: UNICAMP, 1989.

CHAMBERS, Jack K.; TRUDGILL, Peter. Dialectology. Cambridge: Cambridge U. Press, 1980.

COÏANIZ, Alain. Langages, cultures, identités. Paris: L'Harmattan, 2005.

CUNHA, Celso. Língua portuguesa e realidade brasileira. Tempo brasileiro, Rio de Janeiro, n. 13, 10. ed., 1984.

COSERIU, Eugenio. La geografía linguística. 4. ed. Montevideo: Universidad de la Republica, 1965. (Cuaderno n. 11) 
EL-MURR, Victoria; EL-MURR, Joubran; PORTAL, Maria da Glória Alves. Alguns aspectos da colonização alemã em Domingos Martins - 1847/1889. In: COLÓQUIO DE ESTUDOS TEUTOBRASILEIROS, 3., Porto Alegre, 1980. Anais... Porto Alegre, UFRGS: 1980 . p. 305-350.

FERNÁNDEZ, Gretel M. Eres. A lingüística contrastiva é uma área de estudo fora de época? In: DURÃO, Adja B. de Amorim Barbieri (Org.) Lingüística contrastiva: teoria e prática. Londrina: Moriá, 2004. p. 3-9.

FERREIRA, Carlota; CARDOSO, Suzana. A dialetologia no Brasil. São Paulo: Contexto, 1994.

FLEURI, Reinaldo Matias (Org). Intercultura: estudos emergentes. Ijuí: Unijuí, 2001.

GARCÍA, Ofelia. Bilingual education. In: COULMAS, Florian (Ed.). The handbook of sociolinguistics. Oxford: Blackwell Publishers Ltd., 1977. p. 405-420.

HAESE, Aline. As variantes fonético-fonológicas relacionadas à estrutura silábica do português falado por crianças descendentes de pomeranos. Vitória. UFES/PIBIC, 2007.

. Realizações dos ditongos do português por crianças descendentes de pomeranos. Vitória: UFES/PIBIC 2006.

HAMEL, Rainer Enrique. La política del lenguaje y el conflicto interétnico; problemas de investigación sociolingüística. In: ORLANDI, Eni Puccinelli (Org.). Política lingüística na América Latina. Campinas: Pontes, 1988.

KOCH, Walter; KLASSMANN, Mário Silfredo; ALTENHOFEN, Cléo Vilson. Atlas Lingüístico-Etnográfico da Região Sul do Brasil - ALERS. Volumes I e II. Introdução. Porto Alegre; Florianópolis; Curitiba: UFRGS; UFSC; UFPR, 2002.

LYONS, John. Introdução à lingüística teórica. Trad. R. V. Mattos; H. Pimentel. São Paulo: Nacional, 1979. 
MOTA, Jacyra Andrade; CARDOSO, Suzana A. Marcelino (Orgs.). Documentos 2: Projeto Atlas Lingüístico do Brasil. Salvador: Quarteto, 2006.

ORLANDI, Eni Puccinelli (Org.). Política lingüística na América Latina. Campinas: Pontes, 1988.

PETRONE, Pasquale. Aspectos geográficos da área de colonização antiga do estado do Espírito Santo. Vitória: IHGES, 2004.

PRADE, Helga Guttenkunst. O linguajar do alemão gaúcho. In: CUNHA, Jorge; GÄRTNER, Angelina. Imigração alemã no Rio Grande do Sul: história, linguagem, educação. Santa Maria: UFSM, 2003. p. 81-100.

RODRIGUES, Catarina. Atlas prévio do Espírito Santo: primeiras notícias. In: AGUILERA, Vanderci de Andrade (Org.). A geolingüística no Brasil: trilhas seguidas, caminhos a percorrer. Londrina: Eduel, 2005. p. 319-332.

Variação lingüística e diacronia. Anais do II EDIP. Araraquara, UNESP, 2002. p. 255-262.

Áreas lingüísticas no Rio Grande do Sul: conjunto de fatores determinantes. In: CONGRESSO INTERNACIONAL DA ASSOCIAÇÃO DE LINGUÍSTICA E FILOLOGIA DA AMÉRICA LATINA, 11., Campinas, 1988. Atas... Campinas: IELUNICAMP, 1988. p. 13-20.

ROSSI, Nelson. Atlas prévio dos falares baianos. Introdução. Questionário comentado. Elenco de respostas transcritas. Rio de Janeiro: Instituto Nacional do Livro/MEC, 1965.

SCHIFFMAN, Harold. Diglossia as a sociolinguistic situation. In: COULMAS, Florian (Ed.). The handbook of sociolinguistics. Oxford: Blackwell Publishers Ltd., 1977. p. 205-216.

TRESSMANN, Ismael. Dicionário enciclopédico pomeranoportuguês. Santa Maria de Jetibá: SEC, 2006. 